\title{
Antiandrogen withdrawal syndrome (AAWS) in the treatment of patients with prostate cancer
}

\author{
Gianmarco Leone1,*, Marcello Tucci1,*, Consuelo Buttigliero1, Clizia Zichi', Daniele Pignataro', Paolo Bironzo1,

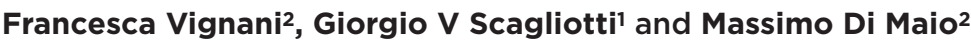

1Division of Medical Oncology, Department of Oncology, University of Turin, San Luigi Gonzaga Hospital, Turin, Italy

2Division of Medical Oncology, Ordine Mauriziano Hospital, Turin, Italy

Correspondence should be addressed to M Tucci: marcello.tucci@gmail.com

*(G Leone and M Tucci contributed equally to this work)

\begin{abstract}
Antiandrogen withdrawal syndrome is an unpredictable event diagnosed in patients with hormone-sensitive prostate cancer treated with combined androgen blockade therapy. It is defined by prostate-specific antigen value reduction, occasionally associated with a radiological response, that occurs 4-6 weeks after first-generation antiandrogen therapy discontinuation. New-generation hormonal therapies, such as enzalutamide and abiraterone acetate, improved the overall survival in patients with metastatic castrationresistant prostate cancer, and recent trials have also shown the efficacy of abiraterone in hormone-sensitive disease. In the last few years, several case reports and retrospective studies suggested that the withdrawal syndrome may also occur with these new drugs. This review summarizes literature data and hypothesis about the biological rationale underlying the syndrome and its potential clinical relevance, focusing mainly on newgeneration hormonal therapies. Several in vitro studies suggest that androgen receptor gain-of-function mutations are involved in this syndrome, shifting the antiandrogen activity from antagonist to agonist. Several different drug-specific point mutations have been reported. The association of the withdrawal syndrome for enzalutamide and abiraterone needs confirmation by additional investigations. However, new-generation hormonal therapies being increasingly used in all stages of disease, more patients may experience the syndrome when stopping the treatment at the time of disease progression, although the clinical relevance of this phenomenon in the management of metastatic castration-resistant prostate cancer remains to be defined.
\end{abstract}

Endocrine-Related Cancer (2018) 25, R1-R9

\section{Introduction}

In recent years, the treatment of patients with metastatic prostate cancer $(\mathrm{PCa})$ has radically changed, with the availability of new antiandrogen hormonal therapies. However, this disease still remains a major health issue in the Western countries, being the second leading cause of cancer-related death in men (Siegel et al. 2016). The natural history of metastatic PCa consists usually of two phases. In the first phase, usually denominated 'hormone-sensitive disease', the disease is usually effectively controlled by androgen deprivation therapy (ADT). The crucial role of androgen receptor (AR) in disease development and progression (Parker et al. 2015) makes PCa extremely 
sensitive to surgical or biochemical castration. Moreover, recent findings showed that in patients with high-risk and/or high-volume hormone-sensitive metastatic disease, the addition of docetaxel to ADT when compared to ADT alone induces a significant improvement in the overall survival (Sweeney et al. 2015, James et al. 2016). Similar results have been recently presented for the combination of abiraterone acetate and ADT (Fizazi et al. 2017, James et al. 2017). Despite the initial therapeutic success, after a median of 24-36 months (Scher et al. 2004), resistance to ADT eventually arises, that delimits the beginning of the second phase, the 'castration-resistant prostate cancer' (CRPC). It was previously believed that the development of CRPC was invariably associated with complete resistance to antiandrogen therapies, because it was believed that PCa cell growth was independent from AR activation. Currently, there is evidence supporting a key role of the AR in all the phases of PCa, and AR and intratumoral steroidogenesis modifications drive the evolution to CRPC. Neoplastic cells acquire the capability to grow in an environment characterized by low androgens levels, because of the upregulation of specific enzymes involved in androgen synthesis, such as CYP17 $\alpha$-hydroxylase and C17-20-lyase (CYP17), AR gene overexpression and mutations, AR splice variants expression and increased expression of transcriptional coactivators (Buttigliero et al. 2015, McCrea et al. 2016).

These findings suggest that the transition from hormone-sensitive disease to CRPC is not related to a real androgen resistance, but rather to functional adaptation of PCa cells. Consequently, there is a continuous response to hormonal stimulation, despite the persisting, dramatic reduction of circulating androgen levels (Buttigliero et al. 2015). The better understanding of tumor biology and progression led to the development of newgeneration hormonal therapies (such as abiraterone and enzalutamide), able to interfere with AR signaling pathway or to suppress CYP17 activity.

The antiandrogen withdrawal syndrome (AAWS) is defined as a further significant $(>50 \%)$ reduction in prostate-specific antigen (PSA) values after the discontinuation of antiandrogen therapy, in the context of combined androgen blockade (CAB) treatment. CAB, also called combined hormone blockade or total hormone blockade, is the combination of an antiandrogen and surgical or biochemical castration. Initially observed in patients withholding the antiandrogen flutamide (Kelly \& Scher 1993), AAWS has been subsequently documented in patients treated with other first-generation antiandrogen drugs, such as bicalutamide and nilutamide.
From a biological point of view, AAWS is strictly associated with specific AR mutations that are inducing a gain of function of $\mathrm{AR}$ and the subsequent conversion of antiandrogens into full-fledged androgens, aberrantly replacing testosterone and DHT.

Before the advent of new-generation hormonal therapies, in patients withholding bicalutamide and continuing ADT in the presence of serological progression only, AAWS was used to justify the delay of the beginning of chemotherapy with docetaxel.

The observed response rate can be as high as 30\% and might be directly associated with treatment duration with AR blockers (Paul \& Breul 2000). With the newgeneration hormonal therapies, such as enzalutamide and abiraterone acetate, many authors questioned whether an AAWS with these new drugs exists. The purpose of this paper was to review the evidence about the classic AAWS with first-generation antiandrogen therapies and to gather initial findings on the relevance of a possible withdrawal syndrome with enzalutamide and/or abiraterone.

\section{The AR machinery}

The $A R$ gene is located on chromosome Xq11-12 and has eight exonic sequences. Wild-type AR is a $110-\mathrm{kDa}$ nuclear protein, which belongs to the steroid hormone receptor family. Four different domains are identified: the N-terminal transactivation domain (NTD), the DNA-binding domain (DBD), a hinge region and the ligand-binding domain (LBD) (Gelmann 2002). Many endogenous hormones can activate the AR, while some others act like antagonists (Li \& Al-Azzawi 2009). However, in normal conditions, LDB binds only dihydrotestosterone (DHT) and, with lower affinity, testosterone (TST). The NTD, encoded by exon 1, is the ultimate AR activity mediator, with mechanisms that are not strictly dependent from ligand-LBD interaction. Indeed, if the NTD is preserved, C-terminal LBD deletions could result in a constitutive active receptor, whereas deletions in NTD, especially in central and $3^{\prime}$ regions of exon 1, significantly reduce receptor activity (Simental et al. 1991). This is a unique characteristic not shared with other steroid hormonal receptors.

The final result of AR activation is an increase in the transcription of several genes, many involved in cell growth, proliferation and inhibition of apoptosis (Heemers \& Tindall 2007).

TST and DHT are natural AR ligands (Li \& Al-Azzawi 2009). In the testis, production of TST is regulated by the hypothalamus-pituitary axis (Pitteloud et al. 2008). 
Testes secrete about $7000 \mu \mathrm{g} /$ day of TST, while very little amount of DHT (about $69 \mu \mathrm{g} /$ day) is directly released by the Leydig cells (Hammond et al. 1977). Circulating TST is mostly bound to plasma proteins, primarily to sex hormone-binding globulin (SHBG) and albumin. TST is converted into the most active androgen, DHT, by steroid 5-alpha-reductase (SRD5A) an enzyme with two isoforms, termed SRD5A1 and SRD5A2 (Thigpen et al. 1993). While SRD5A2 is the dominant isoenzyme in normal prostate tissue, increased levels of SRD5A1 are linked to CRPC progression. Moreover, in CRPC androstenedione replaces TST as the main substrate for SRD5A1, that converts androstenedione to $5 \alpha$-androstanedione, that is then converted to DHT (Chang et al. 2011). DHT is the most potent endogenous AR ligand in humans, showing higher affinity, greater stability and a slower rate of dissociation than TST. Its concentration in the prostate gland is 10 -fold higher than that in serum, which is relevant for prostate diseases, such as benign prostatic hyperplasia and $\mathrm{PCa}$ (Randall 1994).

\section{Pharmacokinetics of antiandrogens}

Bicalutamide is a competitive and pure AR antagonist in vitro and an antiandrogen in vivo. Currently, it is the most commonly used antiandrogen, in combination with LH-RH analogues and, to a lesser extent, in monotherapy, because of its long half-life (about 6 days), higher potency and better tolerability when compared to flutamide (Mahler et al. 1998). It is usually administrated at the dose of $50 \mathrm{mg} /$ day when used as part of the CAB, and at the dose of $150 \mathrm{mg} /$ day when used as single agent. In laboratory animal studies, bicalutamide shows complete selective peripheral activity that has not been confirmed in humans, probably correlated to differences in the blood-brain barrier permeability (Cockshott 2004). Therefore, bicalutamide as single agent leads to an increase of LH levels and, consequently, in the TST production by testis. Bicalutamide is administered as racemate, but its in vivo activity is due to the R-isomer, as the S-isomer is quickly cleared and loosely binds AR and R-bicalutamide has about 30-fold less affinity compared to DHT (Gao et al. 2006).

\section{First-generation antiandrogens withdrawal syndrome}

For a long time, first-generation non-steroidal antiandrogens (NSAA) have represented the best available hormonal therapy for metastatic or unresectable prostate tumors, controlling the disease and postponing chemotherapy. Subsequently, their role has been downsized by the introduction of LHRH analogues. However, bicalutamide is still widely used in the treatment of PC, as its administration increases and maximizes the efficacy of ADT. Adding an AR antagonist to androgen suppression in the CAB strategy is an effective and welltolerated treatment of PCa that significantly prolongs the overall survival (Akaza 2011). Eventually, resistance to $\mathrm{CAB}$ occurs at some point, usually with a rise in PSA values. In several studies, the occurrence of resistance has been correlated to an increased number of AR copies expressed by prostatic cancer cells and to increased production of intra-tumoral androgens (Nemes et al. 2014). However, in a less relevant but clinically significant percentage of patients (about 10\%), resistance is due to specific AR mutations. These mutations can induce a gain of function of $A R$ and a significant change in the interaction between AR and its antagonist. Hara and coworkers have first identified two AR mutations (W741C/L) that allow PCa cell lines growth after 6-13 weeks in vitro exposure to bicalutamide (Hara et al. 2003). The study suggests that these specific mutations switch the activity of bicalutamide from antagonist to agonist. This finding was further confirmed by a structural analysis of the interaction between bicalutamide and W741L AR LBD, with a 2-fold increase in binding affinity (Bohl et al. 2005). W741L AR-positive tumor cells, if stimulated by bicalutamide, show a significant upregulation of the MAPK pathway compared to tumor cells carrying wildtype AR (Terakawa et al. 2010). Even before bicalutamide, flutamide was reported to act as an agonist for T877S and H874Y AR (Fenton et al. 1997). Interestingly, flutamide is still able to inhibit the W741L/C AR, demonstrating that the interaction of the antiandrogens with the AR depends on specific sequences within LBD (Urushibara et al. 2007). Regardless, following studies failed to demonstrate an association between AR mutations found in metastatic CRPC samples and AAWS (Hu et al. 2010). Flutamide and bicalutamide have been proven to have agonist properties in cells engineered to express higher AR levels (Tran et al. 2009). Clones with AR gene amplification are commonly induced in vivo by long-term antiandrogen exposure (McCrea et al. 2016).

As a clinical consequence, patients who develop these mutations can benefit from a suspension of antiandrogen treatment. Practically, a clinical observation time of 4-6 weeks is needed to confirm the AAWS, due to the long half-life of both antiandrogens and PSA. The AAWS has been more frequently reported in early studies, 
associated with a longer progression-free survival and greater improvement in quality of life (Dupont et al. 1993), probably due to both the different drugs used and the development of more accurate diagnostic techniques. More recent findings suggest that AAWS can be detected in about $20 \%$ of patients after cessation of AR blockers, with a median progression-free survival of 3 months (Sartor et al. 2008).

Before the approval of enzalutamide and abiraterone for CRPC patients, AAWS could be used to postpone the beginning of chemotherapy in metastatic prostate cancer patients with only serological progression during $C A B$. However, current European guidelines do not mention AAWS as a potential treatment option (Parker et al. 2015), due to the availability in this setting of effective and welltolerated new-generation hormonal therapies.

\section{Enzalutamide withdrawal syndrome (EWS)}

Enzalutamide is the first approved second-generation NSAA for the treatment of CRPC. Many studies reported that enzalutamide binds AR with greater affinity than first-generation NSAA, being 5- to 8-fold more potent than bicalutamide. Moreover, enzalutamide also inhibits AR translocation inside the cell nucleus and prevents DNA binding, acting as a DNA-binding domain antagonist (Tran et al. 2009). Two different phase III trials demonstrated the efficacy of enzalutamide in the treatment of CRCP, both before (Beer et al. 2014) and after (Scher et al. 2012) docetaxel use. Many different mechanisms have been associated with primary and acquired resistance to enzalutamide (McCrea et al. 2016). The development of aberrant truncated AR variants, such as ARV-7 and ARV-567, seems to play a central role in CRCP progression (Buttigliero et al. 2015). Antonarakis and coworkers reported a significantly lower response rate in patients treated either with enzalutamide or abiraterone who expressed ARV-7 in circulating tumor DNA compared to patients without ARV-7 (0\% vs 53\%, $P=0.004$ for enzalutamide; $0 \%$ vs $68 \%, P=0.004$ for abiraterone) (Antonarakis et al. 2014). Furthermore, the activation of alternative growth pathways, independent from AR signaling, along with the cross-talk between AR downstream genes and other steroidal hormone receptors and ligands are probably implicated in disease progression in patients treated with new-generation hormonal therapy (McCrea et al. 2016). However, like first-generation NSAA, enzalutamide resistance can also be caused by some point mutations of the full-length AR protein (Liu et al. 2017). F876L AR is sufficient to induce resistance to enzalutamide in vitro, and its occurrence changes the activity of enzalutamide from antagonist to agonist, suggesting a possible EWS (Korpal et al. 2013). PCa cells stressed by long-lasting antiandrogen therapies can likely activate alternative proliferative pathways not dependent from AR signaling (Tombal 2011). AR-independent tumor clones are usually more aggressive, less differentiated and unlikely to respond to further therapies. Antiandrogens discontinuation can restore AR activity, which can suppress alternative proliferative pathways and decrease disease progression. This alternative explanation of AAWS is likely underestimated in clinical practice, as it is not followed by PSA reduction. In fact, although other signaling could regulate PSA, it is strictly related to AR activity, especially in early stage disease.

The first reports of EWS were two retrospective studies. In the first report, Rodriguez-Vida and coworkers analyzed 30 patients with metastatic CRPC treated with enzalutamide (Rodriguez-Vida et al. 2015). Three patients had a reduction of PSA values after enzalutamide discontinuation, although only one of them matched the criteria for classic withdrawal syndrome (PSA reduction $>50 \%)$. Unfortunately, no factors were found to be adequate predictors of response. In the second study, von Klot and coworkers reported the occurrence of EWS in 31 patients whose data were collected from 6 different centers in Germany (von Klot et al. 2014). No PSA reduction was observed in any of the 31 patients, and authors concluded that if existent, an EWS was at least very rare for enzalutamide in patients with mCRPC after taxane-based chemotherapy and without a clinical role in this setting. This was attributed to the different pharmacodynamics of enzalutamide, but further investigations in different settings were suggested. Both these retrospective analyses included patients who had already undergone chemotherapy with docetaxel. Another case of EWS was described in a patient, beginning 40 days after enzalutamide discontinuation (Phillips 2014). These initial findings were reviewed by Mosca, who pointed out how EWS may be an existing phenomenon, especially in the early phase of CRPC (Mosca 2015). Very recently, Poole and coworkers showed a PSA decline in 5 of 72 metastatic CRPC patients who discontinued enzalutamide after disease progression; unfortunately, median EWS duration of response, until subsequent PSA progression, was only 6 weeks (Poole et al. 2017). 


\section{Abiraterone acetate withdrawal syndrome (AbiWS)}

Abiraterone acetate is an inhibitor of the androgen synthesis, approved for the treatment of CRPC patients, both in pre-docetaxel (Ryan et al. 2013) and postdocetaxel (de Bono et al. 2011) setting. It acts as a CYP17A1 inhibitor, mainly blocking the conversion of pregnenolone and progesterone into their 17 1 -hydroxy derivatives. Abiraterone acetate also has a less relevant activity as a partial AR antagonist (Yin \& Hu 2014). Resistance to treatment with abiraterone acetate is associated with the same mechanisms already described for enzalutamide. Because the interaction between AR and abiraterone is not the main mechanism of action, the rationale of a possible AbiWS is not as immediate as for the direct AR blockers previously discussed. Despite that, some hypotheses have been postulated. Abiraterone acetate is usually administered in combination with prednisone, in order to avoid hypocortisolism and a consequent rise of ACTH levels (Auchus et al. 2014). Glucocorticoid receptor (GR) gene is one of the most upregulated genes in antiandrogen-resistant $\mathrm{PCa}$ and shares many target genes with AR (Arora et al. 2013). Therefore, prednisone may bypass AR blockade and DHT deficiency through GR. GR overexpression has already been associated with enzalutamide resistance, while its role in abiraterone resistance remains to be determined. Stopping the concomitant administration of abiraterone and prednisone may induce the decrease of AR-regulated genes transcription, mediated by GR activation. Moreover, prednisone may act as a ligand for mutated AR in a lowlevel androgens environment. Multiple AR mutations, most notably $\mathrm{L} 701 \mathrm{H} / \mathrm{M} / \mathrm{Q}$, have been shown to modify LBD affinity range, making molecules with similar structure able to strongly stimulate AR (Van De Wijngaart et al. 2010). In a recent case report, even spironolactone withdrawal has been associated with a dramatic response in a patient with metastatic CRPC (Flynn et al. 2017). Thereby, discontinuation of both abiraterone acetate and prednisone may have positive effects in patients who are not responding to the active therapy and bearing mutations of AR that binds prednisone as a partial agonist (Gauthier et al. 2012). However, other authors questioned why this phenomenon has never been described after cessation of steroids administrated for other reasons, such as during taxane-based chemotherapy (Caffo et al. 2013). Moreover, Caffo and Sharifi have recently speculated about steroidal abiraterone metabolites, such as $\Delta 4$-abiraterone (D4A) and $5 \alpha$-abiraterone (5aA) having a role in the AbiWS (Caffo \& Sharifi 2016). D4A is a strong $\mathrm{AR}$ antagonist, whose activity is comparable to enzalutamide (Li et al. 2015), but it is swiftly converted to $5 \mathrm{aA}$, which conversely acts as AR agonist, by steroid$5 \alpha$-reductase. Hence, high $5 \mathrm{aA}$ blood concentrations may facilitate cancer progression if neoplastic cells have already escaped abiraterone acetate blockade (Li et al. 2016). However, data from a single arm phase II study that evaluated the combination of abiraterone acetate and dutasteride did not support the hypothesis of a phase III study of abiraterone with and without dutasteride (Taplin et al. 2016). Finally, other mechanisms still undefined, related to direct AR-abiraterone acetate interaction, could be involved.

Regardless of underlying biological mechanism, in the last few years, AbiWS has been described in several case reports and short series of patients (Gauthier et al. 2012, Caffo et al. 2013, Witjes 2013). The first two papers described two individual patients who experienced a reduction in PSA levels that lasted at least three months after abiraterone withdrawal (Gauthier et al. 2012, Witjes 2013). Caffo and coworkers described a series of nineteen patients who discontinued abiraterone because of progression (Caffo et al. 2013). A major biochemical response, with PSA reduction $\geq 50 \%$, was observed in three patients. The two cases with the longest duration of the response, 5 and 6 months, respectively, performed PET scans after 3 months from abiraterone withdrawal, showing a significant reduction of the uptake values (SUVmax) (Caffo et al. 2013). A retrospective analysis enrolled 218 patients who had discontinued abiraterone acetate due to disease progression (Albiges et al. 2013). While most patients had immediately started a new treatment after abiraterone discontinuation, 66 did not receive immediately a further treatment and were assessed for PSA changes in the weeks after abiraterone discontinuation. A decrease in PSA values was observed in 21 patients $(32 \%)$, and 4 patients $(6 \%)$ had a PSA reduction $>50 \%$, fitting with the definition of withdrawal

Table 1 Retrospective series for withdrawal syndrome with enzalutamide and abiraterone.

\begin{tabular}{|c|c|c|c|}
\hline Authors (year) & Drug tested & Patients & $\begin{array}{l}\text { N\# withdrawal } \\
\text { syndrome (\%) }\end{array}$ \\
\hline Von Klot et al. (2014) & $\overline{\text { Enzalutamide }}$ & 31 & $0(0)$ \\
\hline $\begin{array}{l}\text { Rodriguez-Vida et al. } \\
\text { (2015) }\end{array}$ & Enzalutamide & 30 & $3(10)$ \\
\hline Poole et al. (2017) & Enzalutamide & 72 & $5(7)$ \\
\hline Caffo et al. (2013) & Abiraterone & 19 & $3(16)$ \\
\hline Albiges et al. (2013) & Abiraterone & 66 & $4(6)$ \\
\hline
\end{tabular}


syndrome (Table 1). From these preliminary data, it can be concluded that, although the biological mechanisms are not yet fully elucidated, AbiWS is not a rare clinical event, and its potential role in clinical practice should be better evaluated in the near future.

\section{Discussion}

Hormonal therapy withdrawal syndrome is a complex and heterogeneous phenomenon that can be associated to multiple receptor-ligand interactions, within the biological mechanisms associated with prostate cancer growth and progression. Unfortunately, it should be stated that most patients are not benefiting from withdrawing hormonal therapy at any time of their disease. Moreover, some patients may manifest symptomatic or rapidly progressing disease, even at the beginning of the castration-resistant phase, with a possible deterioration of performance status, that should discourage any 'waitand-see based' strategy and the delay of the beginning of further effective treatments. In those cases, a different effective treatment should be immediately started. Accordingly, considering the availability of new active agents that have been approved in this setting, it is quite challenging to define a space for AAWS in both treatment guidelines and clinical practice.

In addition, current research is moving forward to the early use of new-generation hormonal therapies, as in biochemical-only progression of CRPC or even in hormone-sensitive disease. For instance, data from two recent studies exploring enzalutamide in association with ADT as compared with bicalutamide plus ADT showed great promises. The TERRAIN trial, a randomized phase II study, enrolled 375 patients with asymptomatic or minimally symptomatic metastatic CRPC progressing on ADT and randomized 1:1 to enzalutamide $160 \mathrm{mg}$ per day plus ADT or bicalutamide $50 \mathrm{mg}$ per day plus ADT. Patients treated with enzalutamide showed a 9.9-month improvement in median progressionfree survival (PFS) (15.7 vs 5.8 months) compared with patients in bicalutamide arm (HR: 0.44; 95\% CI $0.34-0.57 ; P<0.0001$ ) (Shore et al. 2016). Another doubleblind phase II study (STRIVE trial) randomized 396 men with metastatic or non-metastatic CRPC to either enzalutamide $160 \mathrm{mg}$ daily and ADT or bicalutamide $50 \mathrm{mg}$ daily and ADT; the primary endpoint was PFS. Enzalutamide significantly improved PFS (median 19.4 vs 5.7 months; HR: 0.24; 95\% CI: $0.18-0.32$; $P<0.001$ ). Similarly, time to PSA progression, proportion of patients with $\geq 50 \%$ PSA response and radiographic
PFS in metastatic patients were all improved in the enzalutamide arm (Penson et al. 2016).

Moreover, interesting results about the activity of abiraterone in metastatic hormone-sensitive disease have been published in 2017.

The LATITUDE trial was a placebo-controlled phase III study, that enrolled 1200 men with newly diagnosed, highrisk metastatic prostate cancer who had not previously received ADT (Fizazi et al. 2017). Patients were randomized to abiraterone acetate plus low-dose prednisone ( $5 \mathrm{mg} /$ day) in combination with ADT (experimental arm) or ADT alone (control arm). Notably, the experimental treatment delayed radiological disease progression by an average of 18 months and reduced the risk of death by $38 \%$, compared with ADT alone.

Another trial, the STAMPEDE study, showed similar results (James et al. 2017). STAMPEDE is a randomized controlled trial with a multi-stage multi-arm platform design. The trial randomized 1917 men with highrisk locally advanced or metastatic prostate cancer to receive abiraterone acetate plus low-dose prednisone ( $5 \mathrm{mg} /$ day) in addition to ADT (experimental arm) or standard hormonal therapy alone (control arm). Adding abiraterone to ADT significantly lowered the relative risk of death by $37 \%$ and the relative risk of treatment failure by $71 \%$ compared to ADT.

The early and long-lasting selective drug pressure induced by new-generation hormonal therapies may promote the growth of clones with mutated AR that exploit these drugs as agonists.

Therefore, with the earlier use of these drugs in the near future, EWS and AbiWS could become more common. Potentially, patients with asymptomatic and slowly progressive disease could undergo a period of observation before switching to another treatment. Moreover, the activation of alternative proliferative pathways independent from $\mathrm{AR}$ due to molecular perturbation of AR signaling pathway can lead to resistance to second-generation hormonal therapies. Preserving AR-dominant clones over other clones could reduce disease aggressiveness, providing another interesting finding about AAWS.

The association of abiraterone and enzalutamide is supported by a strong biological rationale (Buttigliero et al . 2015). This association showed a favorable safety profile in a phase II clinical trial (NCT01650194) (Efstathiou et al. 2014). Mechanisms underlying EWS and AbiWS are also implicated when the combination of abiraterone and enzalutamide are concurrently administered. Therefore, patients who experience progression with the 
combination may still benefit from the monotherapy, withdrawing one of the two drugs. In this scenario, AAWS may have a crucial role, avoiding an early withhold of an effective therapy.

In conclusion, some clinical reports suggest that AAWS could occur, at least in a limited number of patients, even after discontinuation of new-generation hormonal agents. Further studies are obviously needed to understand how much significant AAWS could be in the clinical practice.

\section{Declaration of interest}

The authors declare that there is no conflict of interest that could be perceived as prejudicing the impartiality of this review.

\section{Funding}

This research did not receive any specific grant from any funding agency in the public, commercial or not-for-profit sector.

\section{Author contribution statement}

Gianmarco Leone and Marcello Tucci equally contributed to the review.

\section{References}

Akaza H 2011 Combined androgen blockade for prostate cancer: review of efficacy, safety and cost-effectiveness. Cancer Science 102 51-56. (https://doi.org/10.1111/j.1349-7006.2010.01774.x)

Albiges L, Auclin E, Rousseau B, Boughalem E, Levy A, Loriot Y, Di Palma M, Massard C \& Fizazi K 2013 Is there a withdrawal syndrome with abiraterone acetate (AA)? Journal of Clinical Oncology 31 (6_Suppl) 89. (https://doi.org/10.1200/jco.2013.31.6_suppl.89)

Antonarakis ES, Lu C, Wang H, Luber B, Nakazawa M, Roeser JC, Chen Y, Mohammad TA, Chen Y, Fedor HL, et al. 2014 AR-V7 and resistance to enzalutamide and abiraterone in prostate cancer. New England Journal of Medicine 371 1028-1038. (https://doi.org/10.1056/ NEJMoa1315815)

Arora VK, Schenkein E, Murali R, Subudhi SK, Wongvipat J, Balbas MD, Shah N, Cai L, Efstathiou E, Logothetis C, et al. 2013 Glucocorticoid receptor confers resistance to antiandrogens by bypassing androgen receptor blockade. Cell 155 1309-1322. (https://doi.org/10.1016/j. cell.2013.11.012)

Auchus RJ, Yu MK, Nguyen S \& Mundle SD 2014 Use of prednisone with abiraterone acetate in metastatic castration-resistant prostate cancer. Oncologist 19 1231-1240. (https://doi.org/10.1634/ theoncologist.2014-0167)

Beer TM, Armstrong AJ, Rathkopf DE, Loriot Y, Sternberg CN, Higano CS, Iversen P, Bhattacharya S, Carles J, Chowdhury S, et al. 2014 Enzalutamide in metastatic prostate cancer before chemotherapy. New England Journal of Medicine 371 424-433. (https://doi.org/10.1056/NEJMoa1405095)

Bohl CE, Gao W, Miller DD, Bell CE \& Dalton JT 2005 Structural basis for antagonism and resistance of bicalutamide in prostate cancer. PNAS 102 6201-6206. (https://doi.org/10.1073/pnas.0500381102)

Buttigliero C, Tucci M, Bertaglia V, Vignani F, Bironzo P, Di Maio M \& Scagliotti GV 2015 Understanding and overcoming the mechanisms of primary and acquired resistance to abiraterone and enzalutamide in castration resistant prostate cancer.
Cancer Treatment Reviews 41 884-892. (https://doi.org/10.1016/j. ctrv.2015.08.002)

Caffo O \& Sharifi N 2016 Could steroidal abiraterone metabolites possibly explain abiraterone withdrawal syndrome? European Urology 70 898-899. (https://doi.org/10.1016/j.eururo.2016.06.013)

Caffo O, Palermo A, Veccia A, Maines F, Chierichetti F, Berruti A \& Galligioni E 2013 Biochemical and objective response to abiraterone acetate withdrawal: incidence and clinical relevance of a new scenario for castration-resistant prostate cancer. Urology $\mathbf{8 2}$ 1090-1093. (https://doi.org/10.1016/j.urology.2013.07.029)

Chang K-H, Li R, Papari-Zareei M, Watumull L, Zhao YD, Auchus RJ \& Sharifi N 2011 Dihydrotestosterone synthesis bypasses testosterone to drive castration-resistant prostate cancer. PNAS 108 13728-13733. (https://doi.org/10.1073/pnas.1107898108)

Cockshott ID 2004 Bicalutamide clinical pharmacokinetics and metabolism. Clinical Pharmacokinetics 43 855-878. (https://doi. org/10.2165/00003088-200443130-00003)

de Bono JS, Logothetis CJ, Molina A, Fizazi K, North S, Chu L, Chi KN, Jones RJ, Goodman OB, Saad F, et al. 2011 Abiraterone and increased survival in metastatic prostate cancer. New England Journal of Medicine 364 1995-2005. (https://doi.org/10.1056/NEJMoa1014618)

Dupont A, Gomez JL, Cusan L, Koutsilieris M \& Labrie F 1993 Response to flutamide withdrawal in advanced prostate cancer in progression under combination therapy. Journal of Urology 150 908-913. (https://doi.org/10.1016/S0022-5347(17)35646-X)

Efstathiou E, Titus MA, Wen S, SanMiguel A, Hoang A, De HaasAmatsaleh A, Perabo F, Phung D, Troncoso P, Ouatas T, et al. 2014 Enzalutamide (ENZA) in combination with abiraterone acetate (AA) in bone metastatic castration resistant prostate cancer (mCRPC). Journal of Clinical Oncology 32 (15_Suppl) 5000. (https://doi. org/10.1200/jco.2014.32.15_suppl.5000)

Fenton MA, Shuster TD, Fertig AM, Taplin ME, Kolvenbag G, Bubley GJ \& Balk SP 1997 Functional characterization of mutant androgen receptors from androgen-independent prostate cancer. Clinical Cancer Research 3 1383-1388.

Fizazi K, Tran N, Fein L, Matsubara N, Rodriguez-Antolin A, Alekseev BY, Özgüroğlu M, Ye D, Feyerabend S, Protheroe A, et al. 2017 Abiraterone plus prednisone in metastatic, castration-sensitive prostate cancer. New England Journal of Medicine 377 352-360. (https://doi.org/10.1056/NEJMoa1704174)

Flynn T, Guancial EA, Kilari M \& Kilari D 2017 Case report: spironolactone withdrawal associated with a dramatic response in a patient with metastatic castrate-resistant prostate cancer. Clinical Genitourinary Cancer 15 e95-e97. (https://doi.org/10.1016/j. clgc.2016.08.006)

Gao W, Kim J \& Dalton JD 2006 Pharmacokinetics and pharmacodynamics of nonsteroidal androgen receptor ligands. Pharmacology Research 23 1631-1658. (https://doi.org/10.1097/ OPX.0b013e3182540562.The)

Gauthier H, Bousquet G, Pouessel D \& Culine S 2012 Abiraterone acetate withdrawal syndrome: does it exist? Case Reports in Oncology 5 385-387. (https://doi.org/10.1159/000341564)

Gelmann EP 2002 Molecular biology of the androgen receptor. Journal of Clinical Oncology 20 3001-3015. (https://doi.org/10.1200/ JCO.2002.10.018)

Hammond GL, Ruokonen A, Kontturi M, Konsela E \& Vihko R 1977 The simultaneous radioimmunoassay of seven steroids in human spermatic and peripheral venous blood. Journal of Clinical Endocrinology and Metabolism 45 16. (https://doi.org/10.1210/jcem45-1-16)

Hara T, Miyazaki J \& Araki H 2003 Novel mutations of androgen receptor : a possible mechanism of bicalutamide withdrawal syndrome novel mutations of androgen receptor. Cancer Research 63 149-153.

Heemers HV \& Tindall DJ 2007 Androgen receptor (AR) coregulators: a diversity of functions converging on and regulating the AR 
transcriptional complex. Endocrine Reviews 28 778-808. (https://doi. org/10.1210/er.2007-0019)

Hu R, Denmeade SR \& Luo J 2010 Molecular processes leading to aberrant androgen receptor signaling and castration resistance in prostate cancer. Expert Review of Endocrinology and Metabolism $\mathbf{5}$ 753-764. (https://doi.org/10.1586/eem.10.49)

James ND, Sydes MR, Clarke NW, Mason MD, Dearnaley DP, Spears MR, Ritchie AWS, Parker CC, Russell JM, Attard G et al. 2016 Addition of docetaxel, zoledronic acid, or both to fi rst-line long-term hormone therapy in prostate cancer (STAMPEDE): survival results from an adaptive, multiarm, multistage, platform randomised controlled trial. Lancet Oncology 387 1163-1177. (https://doi.org/10.1016/S01406736(15)01037-5)

James ND, de Bono JS, Spears MR, Clarke NW, Mason MD, Dearnaley DP, Ritchie AWS, Amos CL, Gilson C, Jones RJ, et al. 2017 Abiraterone for prostate cancer not previously treated with hormone therapy. New England Journal of Medicine 377 338-351. (https://doi. org/10.1056/NEJMoa1702900)

Kelly WK \& Scher HI 1993 Prostate specific antigen decline after antiandrogen withdrawal: the flutamide withdrawal syndrome. Journal of Urology 149 607-609. (https://doi.org/10.1016/S00225347(17)36163-3)

Korpal M, Korn JM, Gao X, Rakiec DP, Ruddy DA, Doshi S, Yuan J, Kovats SG, Kim S, Cooke VG, et al. 2013 An F8761 mutation in androgen receptor confers genetic and phenotypic resistance to MDV3100 (enzalutamide). Cancer Discovery 3 1030-1043. (https://doi.org/10.1158/2159-8290.CD-13-0142)

Li J \& Al-Azzawi F 2009 Mechanism of androgen receptor action. Maturitas 63 142-148. (https://doi.org/10.1016/j. maturitas.2009.03.008)

Li Z, Bishop AC, Alyamani M, Garcia JA, Dreicer R, Bunch D, Liu J, Upadhyay SK, Auchus RJ \& Sharifi N 2015 Conversion of abiraterone to D4A drives anti-tumour activity in prostate cancer. Nature $\mathbf{5 2 3}$ 347-351. (https://doi.org/10.1038/nature14406)

Li Z, Alyamani M, Li J, Rogacki K, Abazeed M, Upadhyay SK, Balk SP, Taplin M-E, Auchus RJ \& Sharifi N 2016 Redirecting abiraterone metabolism to fine tune prostate cancer anti-androgen therapy Zhenfei. Nature 8 583-592. (https://doi.org/10.1002/aur.1474. Replication)

Liu H, Wang L, Tian J, Li J \& Liu H 2017 Molecular dynamics studies on the enzalutamide. Journal of Cellular Biochemistry 118 2792-2801. (https://doi.org/10.1002/jcb.25928)

Mahler C, Verhelst J \& Denis L 1998 Clinical pharmacokinetics of the antiandrogens and their efficacy in prostate cancer. Clinical Pharmacokinetics 34 405-417. (https://doi.org/10.2165/00003088199834050-00005)

McCrea E, Sissung TM, Price DK, Chau CH \& Figg WD 2016 Androgen receptor variation affects prostate cancer progression and drug resistance. Pharmacological Research 114 152-162. (https://doi. org/10.1016/j.phrs.2016.10.001)

Mosca A 2015 Enzalutamide withdrawal syndrome: is there a rationale? BJU International 115 348-349. (https://doi.org/10.1111/bju.12908)

Nemes A, Tomuleasa C \& Kacso G 2014 The androgen receptor remains a key player in metastatic hormone-refractory prostate cancer. Implications for new treatments. Journal of Balkan Union of Oncology 19 357-364.

Parker C, Gillessen S, Heidenreich A \& Horwich A 2015 Cancer of the prostate: ESMO Clinical Practice Guidelines for diagnosis, treatment and follow-up. Annals of Oncology 26 v69-v77. (https://doi. org/10.1093/annonc/mdv222)

Paul R \& Breul J 2000 Antiandrogen withdrawal syndrome associated with prostate cancer therapies. Drug Safety 23 381-390. (https://doi. org/10.2165/00002018-200023050-00003)

Penson DF, Armstrong AJ, Concepcion R, Agarwal N, Olsson C, Karsh L, Dunshee C, Wang F, Wu K, Krivoshik A, et al. 2016 Enzalutamide versus bicalutamide in castration-resistant prostate cancer: the
STRIVE trial. Journal of Clinical Oncology 34 2098-2106. (https://doi. org/10.1200/JCO.2015.64.9285)

Phillips R 2014 Prostate cancer: an enzalutamide antiandrogen withdrawal syndrome. Nature Reviews: Urology 11 366. (https://doi. org/10.1038/nrurol.2014.145)

Pitteloud N, Dwyer AA, DeCruz S, Lee H, Boepple PA, Crowley WF \& Hayes FJ 2008 The relative role of gonadal sex steroids and gonadotropin-releasing hormone pulse frequency in the regulation of follicle-stimulating hormone secretion in men. Journal of Clinical Endocrinology and Metabolism 93 2686-2692. (https://doi. org/10.1210/jc.2007-2548)

Poole A, Gill DM, Hahn AW, Johnson E, Carroll E, Batten JA, Gupta S, Boucher KM, Maughan BL \& Agarwal N 2017 Incidence and characterization of antiandrogen withdrawal syndrome (AAWS) after enzalutamide (ENZA) in patients (pts) with metastatic castrationrefractory prostate cancer (mCRPC). Journal of Clinical Oncology 35 (6_Suppl) 228. (https://doi.org/10.1200/JCO.2017.35.6_suppl.228)

Randall VA 1994 Role of 5 alpha-reductase in health and disease. Bailliere's Clinical Endocrinology and Metabolism 8 405-431. (https://doi.org/10.1016/S0950-351X(05)80259-9)

Rodriguez-Vida A, Bianchini D, Van Hemelrijck M, Hughes S, Malik Z, Powles T, Bahl A, Rudman S, Payne H, De Bono J, et al. 2015 Is there an antiandrogen withdrawal syndrome with enzalutamide? BJU International 115 373-380. (https://doi.org/10.1111/bju.12826)

Ryan CJ, Smith, MR, de Bono JS, Molina A, Logothetis CJ, de Souza P, Fizazi K, Mainwaring P, Piulats J, Ng S et al. 2013 Randomized phase 3 trial of abiraterone acetate in men with metastatic castrationresistant prostate cancer and no prior chemotherapy. New England Journal of Medicine 2 138-148. (https://doi.org/10.1056/ NEJMoa1209096)

Sartor AO, Tangen CM, Hussain MHA, Eisenberger MA, Parab M, Fontana JA, Chapman RA, Mills GM, Raghavan D \& Crawford ED 2008 Antiandrogen withdrawal in castrate-refractory prostate cancer: a Southwest Oncology Group trial (SWOG 9426). Cancer 112 2393-2400. (https://doi.org/10.1002/cncr.23473)

Scher HI, Eisenberger M, D'Amico AV, Halabi S, Small EJ, Morris M, Kattan MW, Roach M, Kantoff P, Pienta KJ, et al. 2004 Eligibility and outcomes reporting guidelines for clinical trials for patients in the state of a rising prostate-specific antigen: recommendations from the Prostate-Specific Antigen Working Group. Journal of Clinical Oncology 22 537-556. (https://doi.org/10.1200/JCO.2004.07.099)

Scher HI, Fizazi K, Saad F, Taplin M-E, Sternberg CN, Miller K, de Wit R, Mulders P, Chi KN, Shore ND, et al. 2012 Increased survival with enzalutamide in prostate cancer after chemotherapy. New England Journal of Medicine 367 1187-1197. (https://doi.org/10.1056/ NEJMoa1207506)

Shore ND, Chowdhury S, Villers A, Klotz L, Robert Siemens D, Phung D, van Os S, Hasabou N, Wang F, Bhattacharya S, et al. 2016 Efficacy and safety of enzalutamide versus bicalutamide for patients with metastatic prostate cancer (TERRAIN): a randomised, double-blind, phase 2 study. Lancet Oncology 17 153-163. (https://doi.org/10.1016/ S1470-2045(15)00518-5)

Siegel RL, Miller KD \& Jemal A 2016 Cancer statistics, 2016. CA: A Cancer Journal for Clinicians 66 7-30. (https://doi.org/10.3322/ caac.21332)

Simental JA, Sar M, Lane MV, French FS \& Wilson EM 1991 Transcriptional activation and nuclear targeting signals of the human androgen receptor. Journal of Biological Chemistry 266 510-518.

Sweeney CJ, Chen Y-H, Carducci M, Liu G, Jarrard DF, Eisenberger M, Wong Y-N, Hahn N, Kohli M, Cooney MM et al. 2015 Chemohormonal therapy in metastatic hormone-sensitive prostate cancer. New England Journal of Medicine 373 737-746. (https://doi. org/10.1056/NEJMoa1503747)

Taplin M-E, McKay RR, Werner L, Mostaghel EA, Lis RT, Voznesensky O, Zhang Z, Marck B, Matsumoto AM, Domachevsky L, et al. 2016 
A phase II trial of abiraterone combined with dutasteride for men with metastatic castration-resistant prostate cancer. Clinical Cancer Research 17 325-331. (https://doi.org/10.1158/1078-0432.CCR-160987)

Terakawa T, Miyake H, Kumano M, Sakai I \& Fujisawa M 2010 The antiandrogen bicalutamide activates the androgen receptor (AR) with a mutation in codon 741 through the mitogen activated protein kinase (MARK) pathway in human prostate cancer PC3 cells. Oncology Reports 24 1395-1399. (https://doi.org/10.3892/ or_00000998)

Thigpen AE, Silver RI, Guileyardo JM, Casey ML, McConnell OD \& Russell DW 1993 Tissue distribution and ontogeny of steroid $5 \alpha$-reductase isozyme expression. Journal of Clinical Investigation 92 903-910. (https://doi.org/10.1172/JCI116665)

Tombal B 2011 What is the pathophysiology of a hormone-resistant prostate tumour? European Journal of Cancer 47 S179-S188. (https://doi.org/10.1016/S0959-8049(11)70163-0)

Tran C, Ouk S, Clegg NJ, Chen Y, Watson PA, Wongvipat J, Smithjones PM, Yoo D, Kwon A, Welsbie D, et al. 2009 Development of a second-generation antiandrogen for treatment of advanced prostate cancer. Science 324 787-790. (https://doi.org/10.1126/ science.1168175.Development)

Urushibara M, Ishioka J, Hyochi N, Kihara K, Hara S, Singh P, Isaacs JT \& Kageyama Y 2007 Effects of steroidal and non-steroidal antiandrogens on wild-type and mutant androgen receptors. Prostate 67 799-807. (https://doi.org/10.1002/pros.20542)

Van De Wijngaart DJ, Molier M, Lusher SJ, Hersmus R, Jenster G, Trapman J \& Dubbink HJ 2010 Systematic structure-function analysis of androgen receptor Leu 701 mutants explains the properties of the prostate cancer mutant L701H. Journal of Biological Chemistry 285 5097-5105. (https://doi.org/10.1074/jbc.M109.039958)

von Klot CAJ, Kramer MW, Böker A, Herrmann TRW, Peters I, Kuczyk MA, Ligges U, Gschwend JE, Retz M, Schmid SC, et al. 2014 Is there an anti-androgen withdrawal syndrome for enzalutamide? World Journal of Urology 32 1171-1176. (https://doi.org/10.1007/s00345-014-1288-3)

Witjes JA 2013 A case of abiraterone acetate withdrawal. European Urology 64 517-518. (https://doi.org/10.1016/j.eururo.2013.06.013)

Yin L \& Hu Q 2014 CYP17 inhibitors - abiraterone, C17,20-lyase inhibitors and multi-targeting agents. Nature Reviews: Urology 11 32-42. (https://doi.org/10.1038/nrurol.2013.274)

Received in final form 17 September 2017

Accepted 27 September 2017

Accepted Preprint published online 28 September 2017 